\title{
The Influence in Airforce Soldiers Through Wearing Certain Types of Army-Issue Footwear on Muscle Activity in the Lower Extremities
}

\author{
Christoph Schulze ${ }^{*}, 1,2$, Tobias Lindner ${ }^{1}$, Katharina Schulz ${ }^{1}$, Susanne Finze ${ }^{1}$, Guenther Kundt ${ }^{3}$, \\ Wolfram Mittelmeier ${ }^{1}$ and Rainer Bader ${ }^{1}$ \\ ${ }^{I}$ Department of Orthopaedics, University of Rostock, Doberaner Str. 142, D-18057 Rostock, Germany \\ ${ }^{2}$ Air Force Medical Squadron, Gnoiener Chaussee, D-18334 Bad Suelze, Germany \\ ${ }^{3}$ Institute for Medical Informatics and Biometry, University of Rostock, Rembrandtstr. 16/17, D-18057 Rostock, \\ Germany
}

\begin{abstract}
The objective of the study was to analyse the influence of the shape and material of the military footwear worn by soldiers on muscle activity in the lower extremities, and whether such footwear could explain specific strain complaints and traumatic lesions in the region of the lower extremities.

37 soldiers (one woman, 36 men) aged between 20 and 53 years underwent a dynamic electromyography (EMG) analysis. Wearing - one pair at a time - five different types of shoes, the subjects were asked to walk on a treadmill, where an EMG of the following muscles was taken: M. tibialis anterior, M. gastrocnemius mediales, M. gastrocnemius laterales, M. peroneus longus and $\mathrm{M}$. rectus femoris.

When the subjects wore old-fashioned outdoor jogging shoes increased muscle activity was observed in the region of the M. peroneus longus. This can be interpreted as a sign of the upper ankle joint requiring increased support and thus explain the higher susceptibility to sprains experienced in connection with these shoes. When the subjects wore combat boots, increased activity was observed in the region of the $\mathrm{Mm}$. tibialis anterior and rectus femoris. The specific activity differences that were observed in particular muscles may have influence in the occurrence of certain disorders, especially in untrained recruits. This can be linked to various strain-related disorders such as shin splints and patello-femoral pain. The data obtained using EMG can provide information about the likelihood of a clustering of the complaints experienced by soldiers during training or active service.
\end{abstract}

Keywords: Musculoskeletal disorders, lower extremities, EMG, military shoes.

\section{INTRODUCTION}

Serving soldiers are expected to maintain high levels of physical activity. Untrained recruits are especially affected by the sudden and taxing demands placed on them [1]. Sports and training-related injuries occur with particular frequency during the initial training period. In the U.S. army, $80-90 \%$ of injuries sustained during this period of basic training are related to the training itself [1], and some of these injuries are related to special equipment [2]. The injuries often occur in the region of the knee and ankle joints and around the spine [3]. The footwear provided to military personnel can be of enormous use in preventing such injuries. It has been shown that the rigidity of the sole affects EMG readings for the lower extremities in runners [4], with muscle activity increasing in line with the hardness of the material. Hinz et al. were able to show that changes in the material of the sole influence the strain placed on the metatarsal region and thus the occurrence of march fractures

*Address correspondence to this author at the Orthopädische Klinik und Poliklinik, Universität Rostock, Doberaner Str. 142, D-18057 Rostock, Germany; Tel: +49(0)381 4949334; Fax: +49(0)381 4949308;

E-mail: christoph.schulze@med.uni-rostock.de
[5]. Gait analyses can be of value in investigating areas of the body which are particularly susceptible to injury, and electromyography (EMG) can be used to document the strain to which specific regions are subject $[6,7]$. In comparative analyses of activity patterns, the most suitable parameters to use are amplitude, peak and the area under the curve (integral) [7]. The objective of the present study was to identify, on the basis of these parameters, the influence of footwear shape and material on the muscles of the lower extremities. In a second step, we analysed if there is a link between strained muscles and the occurrence of musculoskeletal complaints such as shin splints, sprains and strain-related knee pain.

\section{MATERIAL AND METHODOLOGY}

\section{Patients}

37 soldiers $(36: 1=$ male $:$ female) took part in this study on a voluntary basis. Five soldiers did not complete the analysis. The data obtained prior to them breaking off the experiment was, however, used in the evaluation. The study was approved by the Ethical Committee of the University of Rostock (file no.: A 2009 36). All the participants were fully informed about what the study would entail and gave their written consent. The participants were aged between 20 and 
53 (mean age: 29 years, median: 26 years), weighed between 62.5 and $112 \mathrm{~kg}$ (mean weight: $81.5 \mathrm{~kg}$; median weight: $81 \mathrm{~kg}$ ), were between 163 and $193 \mathrm{~cm}$ tall (mean height: $177.8 \mathrm{~cm}$; median: $179 \mathrm{~cm}$ ) and had a BMI of between 21 and $34 \mathrm{~kg} / \mathrm{m}^{2}$ (mean: $25.9 \mathrm{~kg} / \mathrm{m}^{2}$; median: $26 \mathrm{~kg} / \mathrm{m}^{2}$ ). All participants finished their initial training.

After walking barefoot at first the participants wore the shoes listed in Fig. (1) consecutively. The number of participants owning the analysed shoes is listed in the caption of Fig. (1). Detailed information about the investigated footwear is listed up in Table 1. In addition, nine soldiers were analysed wearing privately owned sports shoes, which they classed as comfortable. These shoes were treated as one group. It can be seen as a reference if a comfortable feeling is linked to optimal function. An EMG analysis was taken as the subjects walked on a treadmill at a constant speed of $3.2 \mathrm{~km} / \mathrm{h}$. The ordinary length of stride was measured by video analysis using the Dartfish software (Version 4.0.6.0.; Dartfish; Taufkirchen, Germany) and was about $0.64 \mathrm{~m}(+/-0.01 \mathrm{~m})$.

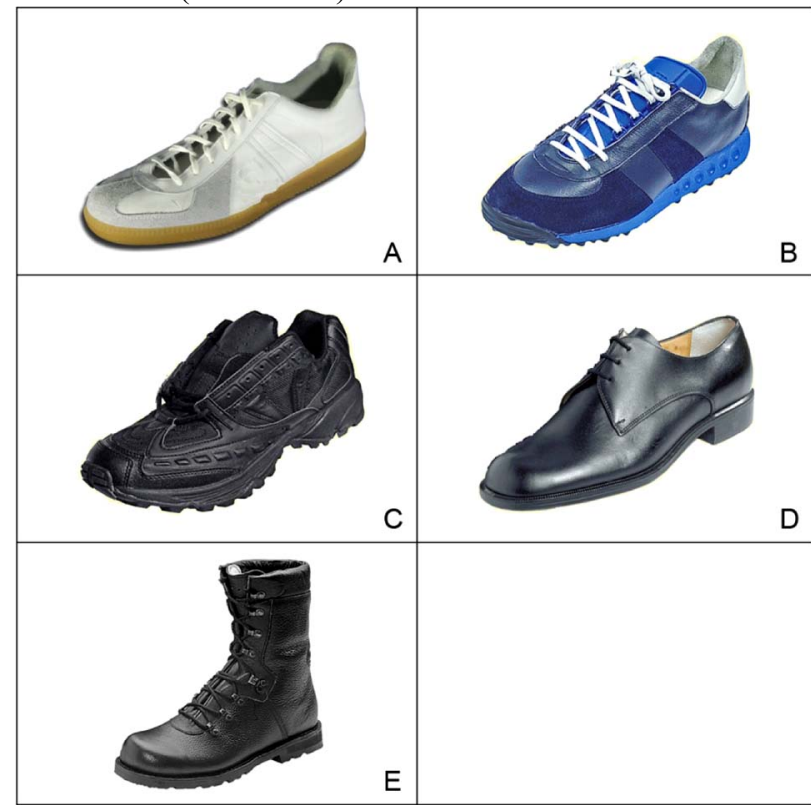

Fig. (1). Shoes used in measurements. A) Indoor (army gym shoes; $n=22$ ); B) Outdoor old (army jogging shoes $B$; $n=9$ ); C) Outdoor new (army sports shoes (UKgear) A/B; $n=11$ ); D) Leather dress shoes (loafers $\mathrm{B} ; \mathrm{n}=26$ ); $\mathbf{E}$ ) Combat boots (army combat boots type $2000 ; n=32)$.

\section{EMG Measurements}

Dynamic surface EMGs of the M. peroneus longus, $\mathrm{M}$. tibialis anterior, M. biceps femoris and M. gastrocnemius medialis and lateralis were taken in accordance to the "standards for reporting EMG data" [8] from the international society of electrophysiology and kinesiology using a wireless EMG System (Noraxon Telemyo 2400T ${ }^{\mathrm{TM}}$, Noraxon, Scotsdale, Arizona, USA). Bipolar recordings were made, using $\mathrm{Ag} / \mathrm{AgCl}$ electrodes (Blue Sensor $\mathrm{P}^{\mathrm{TM}}$, Ambu, Germany) with an active electrode diameter of $7 \mathrm{~mm}$. Prior to the placing of the disposable electrodes the electrode sites were shaved, cleaned with alcohol, dried and slightly roughened with a pad. Fig. (2) shows the placement of the EMG electrodes on a patient's leg. The electrodes were placed both longitudinally and axially over the muscle belly of interest at approximately $40 \mathrm{~mm}$ (centre-to- centre) intervals [9]. The EMG data were sampled at a frequency of $1500 \mathrm{~Hz}$. The signals were amplified, filtered (10$400 \mathrm{~Hz}$ ) and transmitted via a wireless transmitter to a personal computer.

Table 1. Properties of the Investigated Footwear

\begin{tabular}{|c|c|c|}
\hline Model & $\begin{array}{c}\text { Weight } \\
\text { (Dependent to } \\
\text { Size) }\end{array}$ & Properties \\
\hline Leather dress & ca. $530 \mathrm{~g}$ & $\begin{array}{l}\text { - cow leather } \\
\text { - rubber sole } \\
\text { - } 3 \text { hole cording }\end{array}$ \\
\hline Combat boot & ca. $1135 \mathrm{~g}$ & $\begin{array}{l}\text { - adherend rubber sole } \\
\text { - leather with smooth leather lining } \\
\text { - bolstered bootleg } \\
\text { - } 8 \text { hole cording }\end{array}$ \\
\hline Outdoor old & ca. $500 \mathrm{~g}$ & $\begin{array}{l}\text { - leather } \\
\text { - knobbly rubber sole } \\
\text { - bolstered around the ankle joint } \\
\text { - } 6 \text { hole cording }\end{array}$ \\
\hline Outdoor new & ca. $720 \mathrm{~g}$ & $\begin{array}{l}\text { - leather and textile } \\
\text { - moulded rubber sole } \\
\text { - bolstered bootleg and insole } \\
\text { - toe protection } \\
\text { - } 6 \text { hole cording }\end{array}$ \\
\hline Indoor & ca. $600 \mathrm{~g}$ & $\begin{array}{l}\text { - cow leather } \\
\text { - Texon-baking insole } \\
\text { - moulded rubber sole (fine) } \\
\text { - textile lining } \\
\text { - } 6 \text { hole cording }\end{array}$ \\
\hline
\end{tabular}
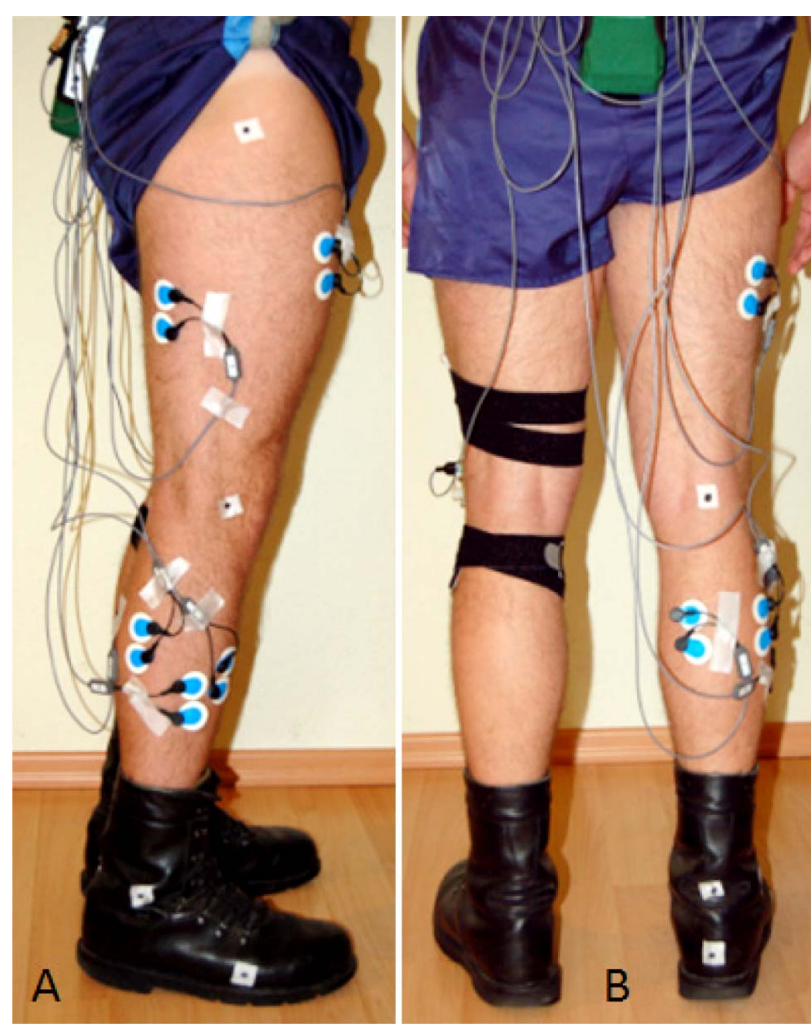

Fig. (2). Placement of EMG electrodes on the right leg. Dynamic surface EMGs of the M. peroneus longus, M. tibialis anterior, M. biceps femoris, Mm. gastrocnemius medialis and lateralis. A) Lateral view: B) Dorsal view. 
Using the software MyoResearch ${ }^{\mathrm{TM}}$ for further processing (Noraxon, Scotsdale, Arizona, USA), the EMG data were full wave rectified, smoothed, and the amplitude normalised. Each recording consisted of at least 5 double steps. After every change of footwear, a warm-up period of about 2 minutes on the treadmill was observed.

\section{Statistical Methods}

Descriptive statistics (median, standard deviation, minimum, maximum) were calculated for each dataset. Each test subject wore several shoes, therefore the Wilcoxon test for dependent samples was used. For this reason it is important to mention that measurements are dependent on the particular test subject. All $p$ values are the result of twotailed statistical tests, with values of $p<0.05$ regarded as significant. All the data were stored and analysed using the statistics program SPSS Version 15.0 (SPSS Inc. Chicago, Illinois, USA).

\section{RESULTS}

An analysis of the EMG data revealed clear footweardependent differences in the activity patterns of the muscles under investigation. Gross activity was determined by calculating the mean amplitude, the peak and the area under the curve (integral) (Fig. 3). The M. peroneus longus displayed a greater activity than observed during barefoot walking for every type of shoe (Fig. 3) except the new-style outdoor sports shoes. They produced lower amplitudes, integrals and peaks than found in barefoot walking. The highest activity values were observed in connection with the old-fashioned outdoor jogging shoes. Even the non-military issued, privately owned trainers produced higher amplitudes and integrals than barefoot walking, and thus an increase in gross muscle activity. However, the peak values were not as high as those observed in connection with the old-fashioned outdoor jogging shoes. A similar trend was observed in connection with the military-issued indoor gym shoes $(p<0.05)$. In case of leather dress shoes and combat boots, the recorded values differed from barefoot walking values by less than 10 percent $(\mathrm{p}<0.05)$.

The results for the M. tibialis anterior were similar to those for the M. peroneus longus. With the exception of the new outdoor sports shoes, which were associated with significantly lower activity patterns, all the shoes investigated produced higher than barefoot walking activity (Fig. 3), although not quite as high as in the M. peroneus longus. Almost all the shoes triggered higher than barefoot walking peaks and integrals, especially the leather dress shoes and the combat boots (integral), where the difference in activity was particularly striking $(\mathrm{p}<0.05)$.

Activity in the Mm. gastrocnemius mediales and laterales was not observed to increase as the result of wearing particular footwear. Indeed, in some cases, a significant decrease on barefoot walking values was observed $(\mathrm{p}<0.05)$ (Fig. 3).

All the shoes investigated, with the exception of the oldfashioned outdoor jogging shoes, triggered higher than barefoot walking amplitudes, peaks and integrals and thus an increase in gross activity in the M. rectus femoris (Fig. 3). The difference is most striking in the case of the combat boots $(\mathrm{p}<0.05)$, which cause an almost $50 \%$ increase on barefoot walking values. The army's new outdoor sports shoes also cause greater than barefoot walking activity and greater activity than the other sports shoes.

The activitiy of the M. biceps femoris showed no significant differences during walking in different shoes.

\section{DISCUSSION}

It is well known that wearing shoes leads to changes in gait in comparison to barefoot walking and results in an elevated walking speed, as well as an increase of step and stride length [10]. Next to their function of active movement, muscles pose a variety of stabilisation functions. The M. peroneus longus, for example, is involved in plantar flexion, pronation and the stabilisation of the longitudinal and transverse arches of the foot. Its role in pronation in particular makes it extremely important in the stabilisation of the ankle joint against sprains [11]. The prevention of sprains is one of the main objectives of footwear designed for sports professionals and soldiers. Stacoff et al. describe a connection between the material composition of a shoe and torsion in the region of the foot [12]. In the present study the highest activity values for the $\mathrm{M}$. peroneus longus were observed in connection with the old outdoor jogging shoes. A possible explanation offers the design of the shoe. Due to the design, the centre of rotation of the ankle joint is shifted cranially by the shoes' thick, knobbly soles. As insufficient lateral stabilisation is provided, muscular activity increases statically in order to stabilise the ankle and hence prevent supination during walking. The new outdoor sports shoes, on the other hand, are associated with lower than barefoot walking values. This again might help to prevent sprained ankles. The difference in activity is seen in all three calculated parameters. As the duration of wearing and the distance covered in a particular type of footwear are important factors [13], the increase in activity measured in connection with military dress shoes is not of huge significance in the triggering of strain-related complaints and traumata of the lower extremities. The intensity of wear of these shoes is simply too low to be of much relevance. The difference between combat boots and barefoot walking walking, and combat boots and other shoes may be down to the fact that the encapsulation of the ankle joint prevents the occurrence of high peak values, but the resistance of the material against even physiological pronation means that higher amplitudes and a larger integral are observed.

The M. tibialis anterior plays a role in dorsal flexion, supination, and, to a lesser extent, in pronation [11]. The high integral and peak values observed for this muscle in connection with dress shoes, old-fashioned outdoor jogging shoes and combat boots may be of clinical significance. The wearing of these types of shoes increased the muscular activity. Too much strain in the region of the M. tibialis anterior is linked with shin splints [14], a condition which occurs frequently in recruits, and with anterior compartment syndrome. As both combat boots and leather dress shoes are sturdy shoes with hard, relatively inflexible soles, their shape and the material from which they are made may well play an important role in the development of musculoskeletal complaints. However, next to material properties, it has to be taken into account that most recruits are simply not used to 


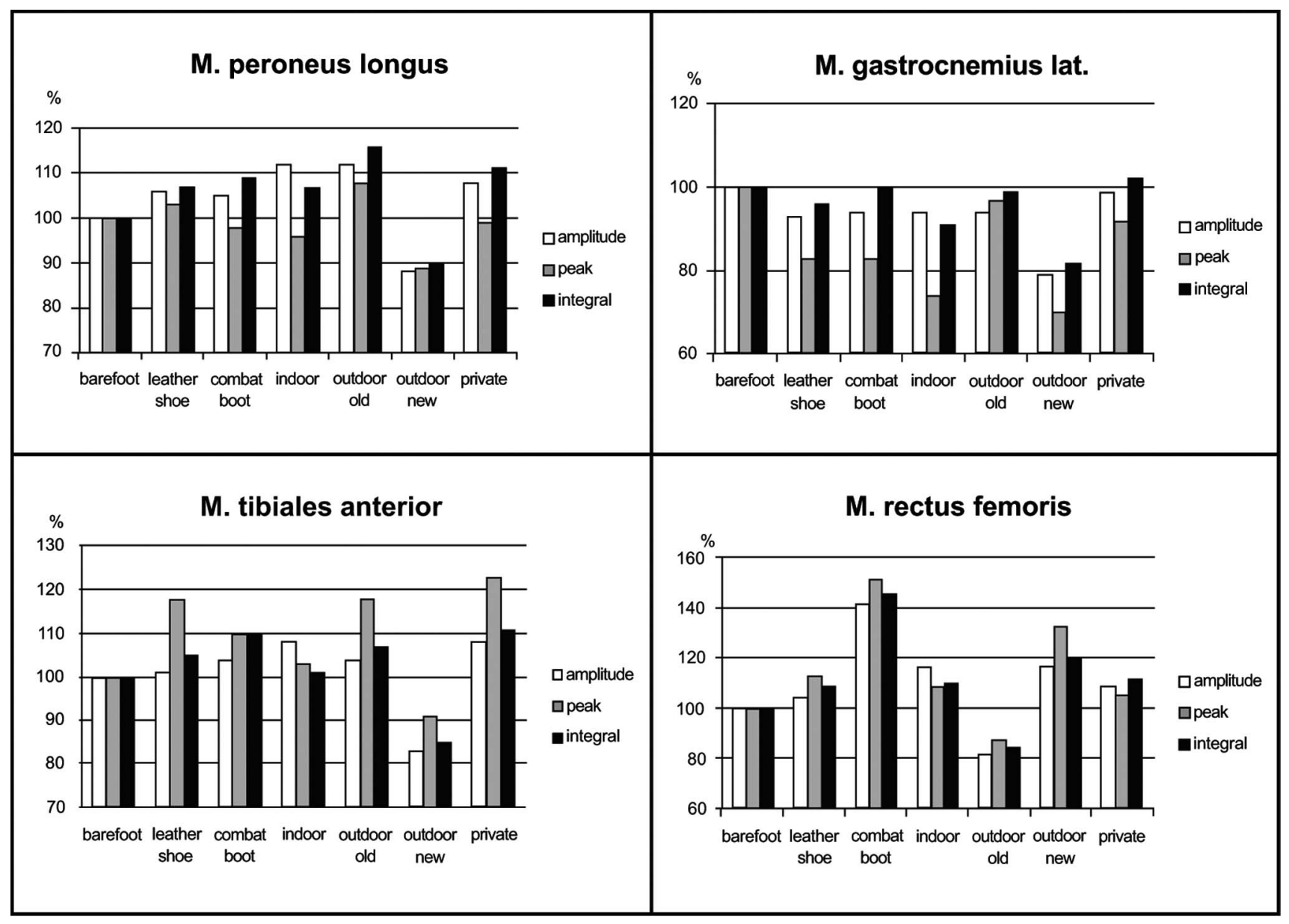

Fig. (3). Results of EMG. Activity (amplitude, peak, integral) in percent compared to barefoot walking measurements. Relative values are presented to make the results comparable.

the distances they are expected to cover and the conditions under which they must do so [13].

The M. rectus femoris flexes the hip and extends the knee [11]. As such, one of its roles in walking is to bear the brunt of the weight of the lower leg, extending it forward and lifting it up against gravity. The increase in activity seen so clearly in connection with the wearing of combat boots may well be a consequence of the weight of the boots compared to other shoes. This theory is supported by the fact that the old-fashioned army jogging shoes, which are very light, trigger lower activity patterns. Activity increase in the EMG of the ventral thigh muscles has been linked to patellofemoral pain syndrome [15]. This is a frequent complaint amongst recruits [3]. It might hence be possible, that there is a connection between footwear, the increase in activity such footwear causes in the $M$. rectus femoris, and the development of the patello-femoral pain syndrome in recruits.

We found significant differences between the investigated shoe models, but obviously, there are certain limitations of this study. Soldiers of all sex, age, weight and activity categories were included and considered in the study. Participants were heterogeneous in provided footwear. This is due to the different times they started their military service. Because of the limited number of voluntary participants this limitations could not have been avoided. Furthermore, only a single walking speed on the treadmill was used and the participants were heterogeneous in their walking characteristics.

We were able to demonstrate that a comfortable feeling, as it is associated with the wearing of private sports shoes, does not automatically lead to advantageous changes in muscle activity in relation to the shoes provided by the military. The fact that footwear can affect muscles of the lower extremities is actually shown by Masai Barefoot Technique $(\mathrm{MBT})^{\mathrm{TM}}$ shoes. Especially M. tibialis anterior and M. gastrocnemius are affected thereby [16].

In summary, this experimental study was able to provide evidence of changes in muscle activity caused by different types of shoes. The results bolster our understanding of the reasons for the occurrence of certain types of strain-related musculoskeletal pain in young recruits and older soldiers. In addition, we were able to show that the shape of footwear and the material from which it is made can cause specific changes in muscle activity in the lower extremities. The influence of shoe shape and material was particularly clear in the case of combat boots, whose sturdy form caused increased activity in the region of the M. tibalis anterior in particular. The thick, knobbly sole and lack of lateral support found in the old-fashioned outdoor jogging shoes caused 
increased activity in the M. peroneus longus. The influence of footwear material was particularly evident in the case of the $M$. rectus femoris, where heavy shoes led to a significant increase in gross muscle activity particularly. EMG investigations make it possible to quantify muscular strain, which means that in the future, EMG tests combined with gait and movement analyses or the use of a goniometer will allow us to make predictions about the occurrence of upper ankle injuries and complaints, shin splints and anterior compartment syndrome.

\section{CONFLICT OF INTEREST STATEMENT}

All the authors disclose any financial and personal relationships they may have with other people or organisations that could inappropriately influence this work.

\section{REFERENCES}

[1] Jones BH, Knapik JJ. Physical training and exercise-related injuries. Surveillance, research and injury prevention in military populations. Sports Med 1999; 27(2): 111-25.

[2] Jones BH, Perrotta DM, Canham-Chervak ML, Nee MA, Brundage JF. Injuries in the military: a review and commentary focused on prevention. Am J Prev Med 2000; 18(3 Suppl): 71-84.

[3] Jennings BM, Yoder LH, Heiner SL, Loan LA, Bingham MO. Soldiers with musculoskeletal injuries J Nurs Scholarship 2008; 40(3): 268-74

[4] Wakeling JM, Pascual SA, Nigg BM. Altering muscle activity in the lower extremities by running with different shoes. Med Sci Sports Exerc 2002; 34(9): 1529-32.

[5] Hinz P, Henningsen A, Matthes G, Jager B, Ekkernkamp A, Rosenbaum D. Analysis of pressure distribution below the metatarsals with different insoles in combat boots of the German Army for prevention of march fractures. Gait \& Posture 2008; (27): 535-8.

[6] Lecompte J, Maisetti O, Guillaume A, Skalli W, Portero P. Neck strength and EMG activity in fighter pilots with episodic neck pain Aviat Space Environ Med 2008; 79(10): 947-52.

[7] Perry J. Ganganalyse - Norm und Pathologie des Gehens. München, Jena: Urban \& Fischer 2003; 240-259; ISBN: 3-43747110-4.

[8] Merletti Rm Politecnico Di Torino. Standards for reporting EMG data. J Electromyogr Kinesiol 1999; 9(1): III-IV

[9] Hermens HJ, Freriks B, Disselhorst-Klug C, Rau G. Development of recommendations for SEMG sensors and sensor placement procedures. J Electromyogr Kinesiol 2010; 10: 361-374.

[10] Lythgo N, Wilson C, Galea M. Basic gait and symmetry measures for primary school-aged children and young adults whilst walking barefoot and with shoes. Gait Posture 2009; 30(4): 502-506.

[11] Schiebler TH Ed. Anatomie. Berlin, Heidelberg, New York: Springer-Verlag 2005; 241-374; ISBN: 3-540-21966-8.

[12] Stacoff A, Kälin X, Stüssi E. The effects of shoes on the torsion and rearfoot motion in running. Med Sci Sports Exerc 1991; 23(4): 482-90.

[13] Knapik JJ, Reynolds KL, Harman E. Soldier load carriage: historical, physiological, biomechanical, and medical aspects. Mil Med 2004; 169(1): 45-56.

[14] Andrish JT, Bergfeld, JA, Walheim J. A prospective study on the management of shin splints. J Bone Joint Surg 1974; 56A (8): 1697-1700.

[15] Ribeiro AC, Grossi DB, Foerster B, Candolo C, Monteiro-Pedro V. Electromyographic and magnetic resonance imaging evaluations of individuals with patellofemoral pain syndrome. Rev Bras Fisioter 2010; 14(3): 221-8.

[16] Romkes J, Rudmann C, Brunner R. Changes in gait and EMG when walking with the Masai Barefoot Technique. Clin Biomech (Bristol, Avon) 2006; 21(1): 75-81. 